\title{
From Dyadic Ties to Information Infrastructures: Care-Coordination between Patients, Providers, Students and Researchers
}

\section{Contribution of the Health Informatics Education Working Group}

\author{
S. Purkayastha', A. Price', R. Biswas ${ }^{3}$, Jai Ganesh A.U., ${ }^{4}$ P. Otero ${ }^{5 *}$ \\ 1 Department of Bio Health Informatics, Indiana University-Purdue University at Indianapolis, Indiana, USA \\ 2 Department of Primary Health Care Sciences, University of Oxford, Oxford UK \\ 3 Department of Medicine, LN Medical College and Research Center, Bhopal, India \\ 4 Sri Sathya Sai Central Trust, Prasanthi Nilayam, Puttaparthi, Andhra Pradesh, India \\ 5 Hospital Italiano de Buenos Aires, Buenos Aires, Argentina
}

\begin{abstract}
Summary
Objective: To share how an effectual merging of local and online networks in low resource regions can supplement and strengthen the local practice of patient centered care through the use of an online digital infrastructure powered by all stakeholders in healthcare. User Driven Health Care offers the dynamic integration of patient values and evidence based solutions for improved medical communication in medical care.

Introduction: This paper conceptualizes patient care-coordination through the lens of engaged stakeholders using digital infrastructures tools to integrate information technology. We distinguish this lens from the prevalent conceptualization of dyadic ties between clinician-patient, patient-nurse, clinician-nurse, and offer the holistic integration of all stakeholder inputs, in the clinic and augmented by online communication in a multi-national setting.

Methods: We analyze an instance of the user-driven health care (UDHC), a network of providers, patients, students and researchers working together to help manage patient care. The network currently focuses on patients from LMICS, but the provider network is global in reach. We describe UDHC and its opportunities and challenges in care-coordination to reduce costs, bring equity, and improve care quality and share evidence.

Conclusion: UDHC has resulted in coordinated global based local care, affecting multiple facets of medical practice. Shared information resources between providers with disparate knowledge, results in better understanding by patients, unique and challenging cases for students, innovative community based research and discovery learning for all.
\end{abstract}

\section{Keywords}

Medical informatics, International Medical Informatics

Association, yearbook, decision support systems

Yearb Med Inform 2015;10:68-74

http://dx.doi.org/10.15265//Y-2015-008

Published online June 30, 2015

\section{Introduction}

\section{From Dyadic Ties to Information Infrastructures}

UDHC has evolved from a traditional dyadic tie between a single patient and physician to its current form where the patient not only sees the same single physician but is also included in a volunteer network of other health professionals contributing to his/her care in the form of a web based conversational archive. The patient is included in the conversation and can contribute to and suggest changes to the patient record.

Initially it began with the single physician emailing his colleagues for help in understanding the available options to meet his/her patient requirements and gradually evolved into an information infrastructure archiving all these electronic conversations inside a web based record. This may not have moved from the dyadic tradition if it were not for a patient's relative who became a social worker and took it upon himself to gather every patient's information requirements and write them by hand and share the record through email initially and later through a web based health record that was kept open after de-identification as per HIPAA (Health Insurance Portability and Accountability Act) guidelines.

\footnotetext{
* All authors have contributed equally to this work
}

The idea of sharing and learning around patients has been alive since the beginning of medicine when physicians would present their cases to a large audience to primarily learn from the inputs of other physicians [1]. From this interchange many published their cases naming themselves after the disease problems they solved. In this way case reporting became a gainful activity not only in terms of scientific advancement toward patient benefits but also as an important instrument of physician fame. Figure 1 shows how UDHC has adapted this tradition in the UDHC blended learning model [2].

In the age of open access and digital technology UDHC has blended traditional learning methods with digital technology to provide a platform where an interested patient and a curious medical student can contribute to progressive value sensitive healthcare. We have utilized this case reporting model to help our patients and to train our medical students about disease and patient experience. The patients expressed interest in learning more about their disease and we are using this same model to teach students and patients together [3] [4]. UDHC discussions take place in Tabula Rasa [5], a term denoting a clean slate in Latin, which exists to present a secure invitation platform for doctors, medical students, patients and 'users' on the popular social network Facebook. Anyone who has a Facebook user name and is invited to contribute following screening by the directors can join in the discussions on this moderated platform. 


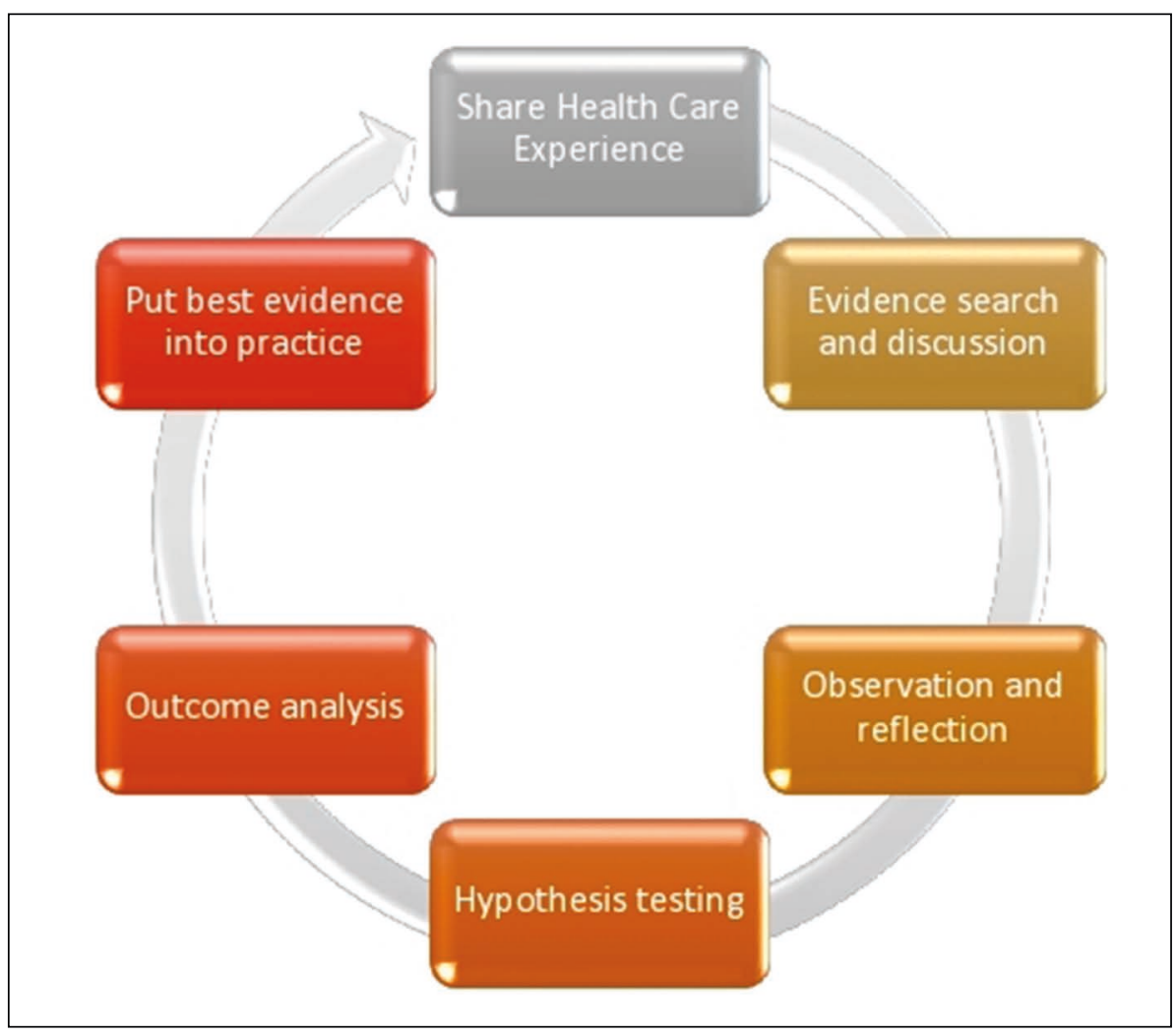

Fig. 1 UDHC blended learning: Evidence to practice cycle

UDHC has developed with a volunteer labor force what the Agency of Healthcare Research and Quality (AHRQ) is advocating as the future on primary care. AHRQ defines care coordination as deliberately organizing patient care activities and sharing information among all of the participants concerned with a patient's care to achieve safer and more effective care [6]. While care coordination by this definition converges topics related to team work, information sharing and care management, patient-centered care coordination is largely understood as home tele-monitoring [7] home tele-care [8], and medical homes [9] AHRQ's atlas framework measures multiple facets of care coordination and focuses on health care at home to describe patient-centered care coordination [6].

While potential approaches to patient-centered care coordination (PCCC) includes teamwork with medical providers, specialist consultants, home health care integration, healthcare Information technology enabled coordination [10], we have yet to see these amalgamated by others in ways that the general public and the vulnerable patient can consistently be empowered to participate in their own healthcare choices [11] and research innovation [12].

Successful information infrastructures are shared, evolving, open, standardized and meet the needs of a heterogeneous population [13]. In literature, we see infrastructures as enablers of coordinated activities between people, processes and technology such that the interplay becomes the foundation that attracts others to use and participate in the network [14]. We appreciate the involvement of PCCC to strengthen this conceptual framework, where patients, providers, programs, health records; technology tools collaborate in the infrastructure to improve health. This has also been labeled as 'User driven healthcare' or UDHC and aims to improve healthcare and medical diagnosis through clinical problem solving by utilizing concerted experiential learning in conversations between multiple users and stakeholders, primarily patients, health professionals, and other actors in a care giving collaborative network across a web interface [3].

\section{Objectives}

The objective is to introduce an interactive blended clinical and online medical infrastructure by sharing a conceptual framework for enrollment of the participants into the infrastructure and logging the expanse of the infrastructure through debates, discussions and problem solving while meeting the challenges that translate into reports of improved patient care.

\section{Aims}

- We aim to show how patients and medical professionals can collaborate as a team to play a central role in initiating and moving the coordination of health care knowledge, participation, research and training forward.

- To facilitate the goal of increasing medical learning while integrating evidence based medicine into practice while respecting and preserving patient values

- To preserve empathy and experiential learning in health care through shared medical problem solving.

\section{Methods}

The UDHC implementation involves two parallel paths through which care coordination takes place. The patient is the initiating collaborator who uploads a patient narrative to the UDHC portal. Information technology is used to provide a data secure and safe environment for the sharing of sensitive information. The second path for the infrastructure involves the participation of providers, patients, students and researchers. The users or stakeholders contribute medical information, resources, peer support and shared values. See Figure 3 for a work-flow of the UDHC process. 


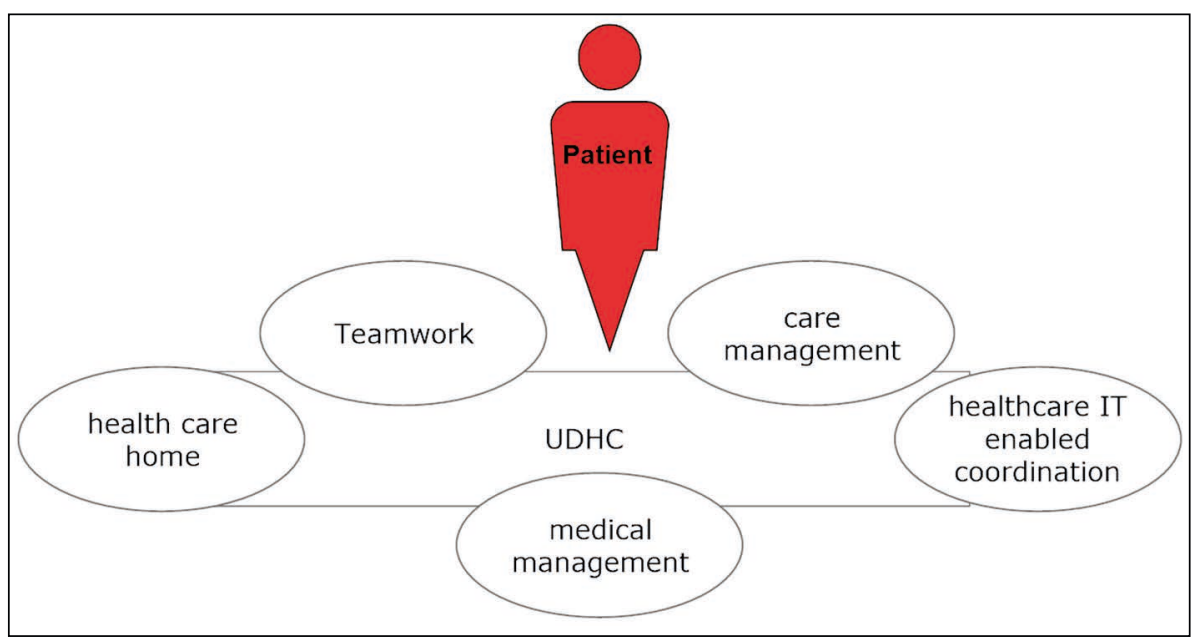

Fig. 2 Patient centered care coordination in UDHC

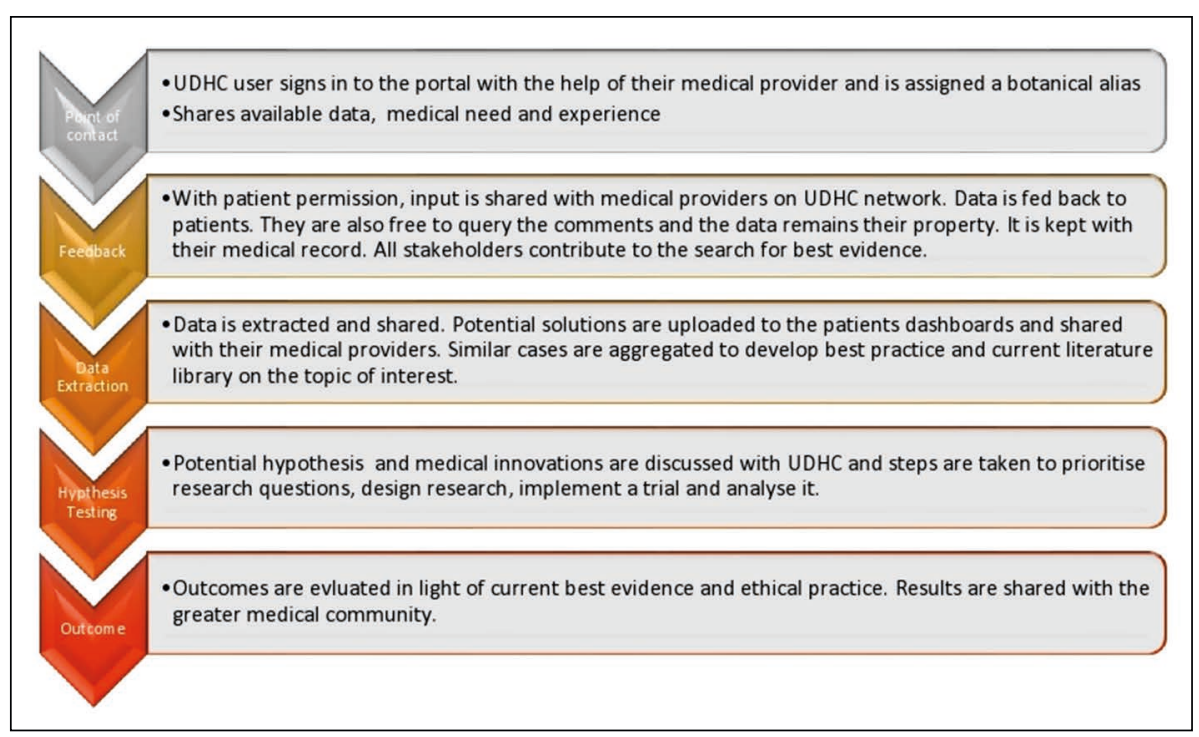

Fig. 3 Steps of UDHC blended learning

\section{Collaboration of UDHC, BMJ and LN Medical College, Bhopal}

Beginning in 2012, The British Medical Journal (BMJ) have initiated a Patient centered learning model also known as a global-health case-reports medical school elective for medical students around the world [15] (details are online here: http://promotions.bmj.com/jnl/ bmj-case-reports-student-electives This initiative is offered in collaboration with
LN Medical College and Research Center, the BMJ. The electives are engineered to help students acquire skills for efficient patient data capture, become proficient in data processing skills and develop skills needed for clinical audit and feedback of an individual patients care to all providers involved in the patients care. Students are mentored in the production of a case report suitable for publication in BMJ case Reports. Every year one exceptional student is granted a BMJ Case Reports Fellowship [15]. Bhopal, India ,Arogya UDHC online and

\section{An Illustration of UDHC Workflow toward Patient Centered Learning Culminating in a BMJ Published Case Report}

Step 1: (Figure 4) The stem of the potential case report is uploaded to the UDHC secure network [16]. The cases are uploaded not only by community health workers across rural India (the maximum number coming from one of our pilot villages in North Bengal) but also by health professional faculty (as illustrated in the instance below). The inputs are then further shared in an online discussion forum called 'tablula-rasa' frequented by global health professionals. A physician (author RB) co-ordinates this process and the group's evidence based output for the benefit of the patient is emailed back to the patient through the community health worker who encourages patients to discuss the group output with his/her local physician before taking any action.

Step 2: Consists of presentation of the case report in Tabula Rasa [5]. This is followed by 'conversation' surrounding the case as depicted in the (Figure 5). In addition to what is formally considered the record, this data may contain inputs from the patients, their loved ones, existing literature and perhaps even community input. These cases can be quite complex with multiple co-morbidities as they are real life patients rather than text book disease examples. This serves as partial preparation for the UDHC interns to manage complex cases in their future practice. Tabula Rasa members discuss the case and offer their inputs which are shared with the patient's medical providers. The local physicians retain their autonomy and role as the patient provider and they and the patient are can choose to act on the discussion of the evidence but there is no formal obligation for them to do so and they remain the treating physician at all times.

In this case (Figure 5) Platypnea-orthodeoxia syndrome [17] is discussed and refers to abnormal oxygenation in the upright position a condition that has been correlated 
with the reopening of foramen ovale and an acute right-to-left intra cardiac shunt.

The discussed case (refer Figures 6 and 7) featured in the secure moderated social media platform is connected to the patient's online health record and is finally published in BMJ Case Reports by [17] where other medical providers can take advantage of best evidence and practice to apply to their own patients. At UDHC BMJ Case Reports are one of the resources used for information on how clinicians have managed similar cases to the ones currently explored.

UDHC is developing a model of person centered health research. In recent times, inspired by our collaborator from Oxford, (author AP), we have embraced a 'citizen science model' for research [18]. UDHC and ThinkWell (a citizen research platform) aim to provide an infrastructure where the public can become informed and responsible shared decision-makers who help prioritize, initiate, design, organize and participate in health research [19]. In India and elsewhere the needs and resources differ from the UK or the USA, therefore we are building a clinical research foundation that will target the needs of the local population through observation and engagement of interested citizens in a collaborative learning atmosphere. We have begun to train 'patients, their primary caregivers and all interested citizens' in the essential elements necessary to understand medicine beginning with anatomy by explaining their diagnosis with examples from the pathology lab and by introducing them to medical students and other patients who can take the time to explain options for their medical future. Users will not only have access to their own medical records and research about their condition but they will also see their disease in a concrete way through anatomy in real time.

This research is very different from the current dominant paradigm of 'population based research' because we treat each and every patient as a research project; a perspective which would not be achieved through the traditional population based lens. This research doesn't focus on scaling or generalization for population statistical outcomes but is content to benefit one individual at a time (as long as it is done with the support of current best evidence and ethics). The returns for the physicians and researchers in this program are in terms of learning and the finding the resources to meet their patient's needs. Although their learning points are gathered and shared as 'case reports' publications, the emotional satisfaction one derives in meeting the needs in an impossible situation is difficult to share in words.

Qualitative research, test and train methods and comparative effectiveness research are used to establish effectiveness of the training and to identify gaps in research understanding. The eagerness of the local population to engage in this way is most promising and the citizens, students and consultants report this training is helping them to better manage their health conditions, contribute to shared decision making, and to aid in intervention compliance.

Unlike other systems, UDHC started with the people and the problem to be solved, they

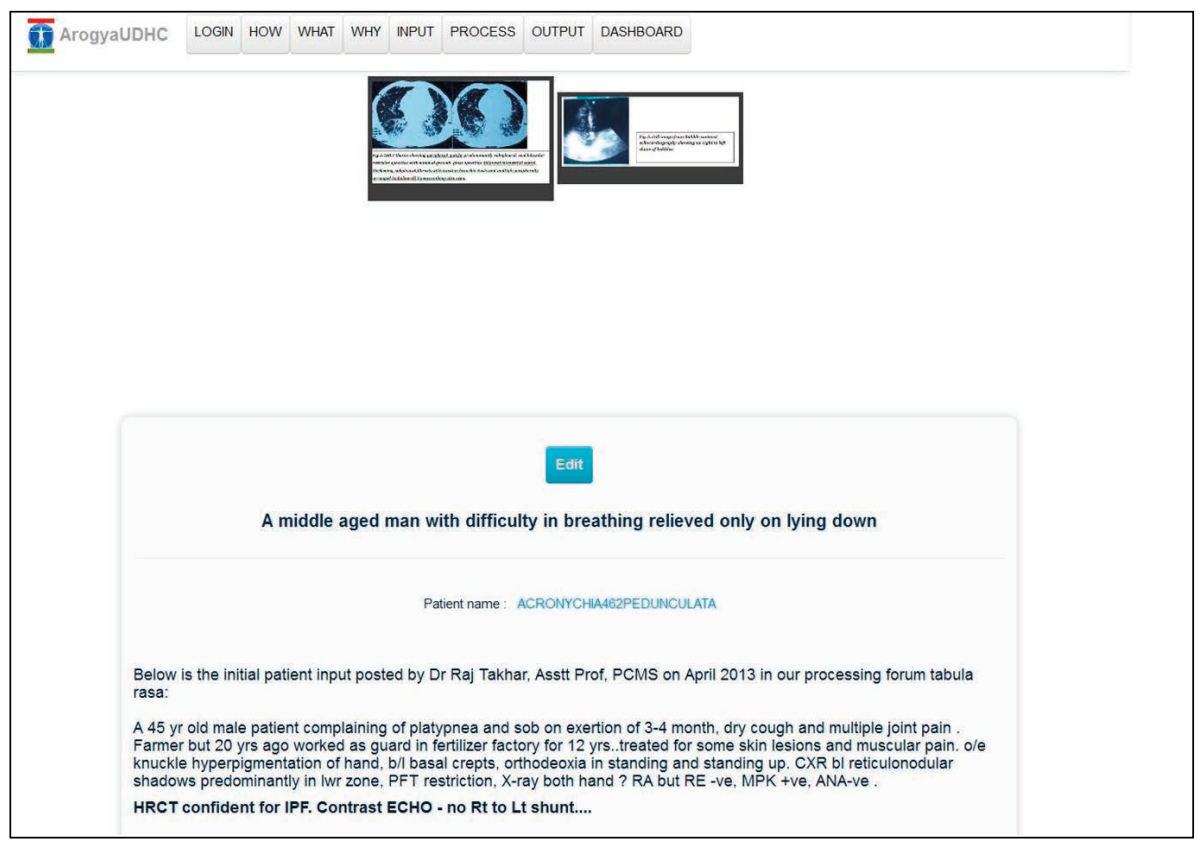

Fig. 4 Initial step of UDHC workflow: Generating an online patient record

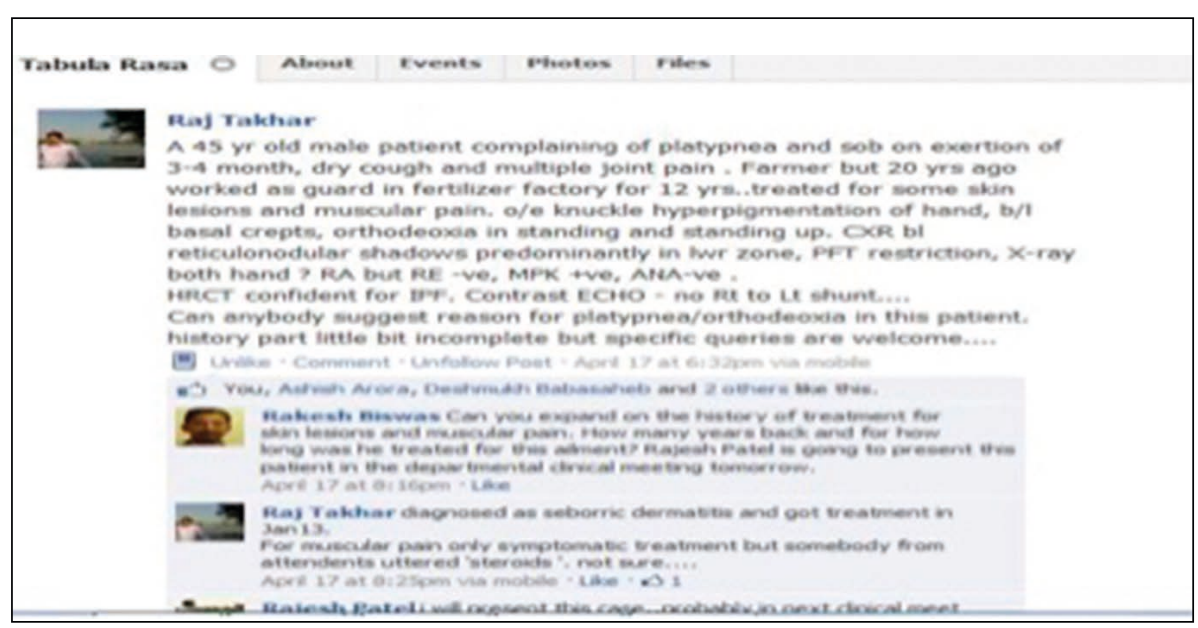

Fig. 5 Conversational learning on Tabula Rasa group 
then used the technology to support progress rather than building technology in anticipation of attracting a population. As the users needs were met through the addition of technology, the population UDHC was able to support increased in numbers. When setbacks in accessibility or usability occur from a technical perspective the population engagement decreases until these problems are solved in a way that meets the UDHC users' needs.

Why do rural patients take the role that we describe is something that is often asked. There are many factors that contribute to citizen patient collaboration including the opportunity to relate to a community health worker who takes a detailed history as opposed to a doctor who would not be able to provide any more time than 5 minutes to a patient. Patients value the feedback from our moderating health professional who is fortified through communications with our network concerning their cases. Emails to their local physician are shared with the patients by our community health worker. This communication is of value in answering the patient's questions and is vastly different from the traditional prescription trajectory between the doctor and the pharmacist. Patients report limited options are traditionally shared in a manner that can be very depressing. One of our recent patients, a poor woman with a double valve heart disease was simply asked to submit to costly surgery and was not provided with any less costly alternatives. This patient and her relatives were distressed and affected by the fact that their local physician gave them a (do or die) goal of repairing the heart valve fixed at a cost they couldn't afford. In this instance we were able in our center to provide the family with a belief a good life is possible even without the repair and the patient quickly demonstrated incredible relief in her symptoms in spite of no other change in treatment and using the same diuretics and rate reducing agents (for her atrial fibrillation).

UDHC is encouraged by the success of award winning initiatives developed by UDHC leaders, social entrepreneurs and students in the R3G Foundation [20]. These include KMES, a project which matches patients with available emergency rooms; Save a Girl, the text based plan to reduce

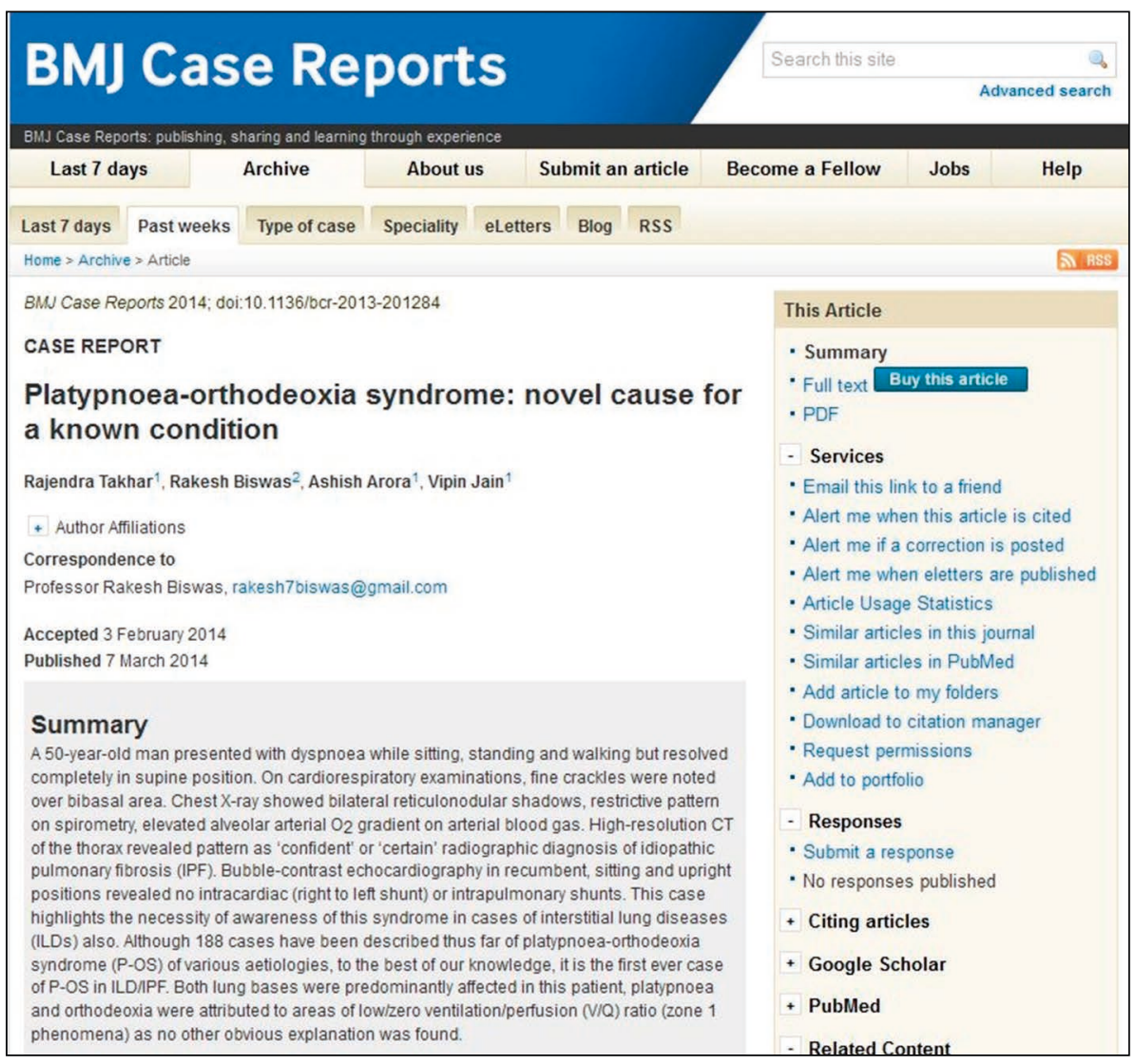

Fig. 6 From UDHC to group discussion to BMJ case reports

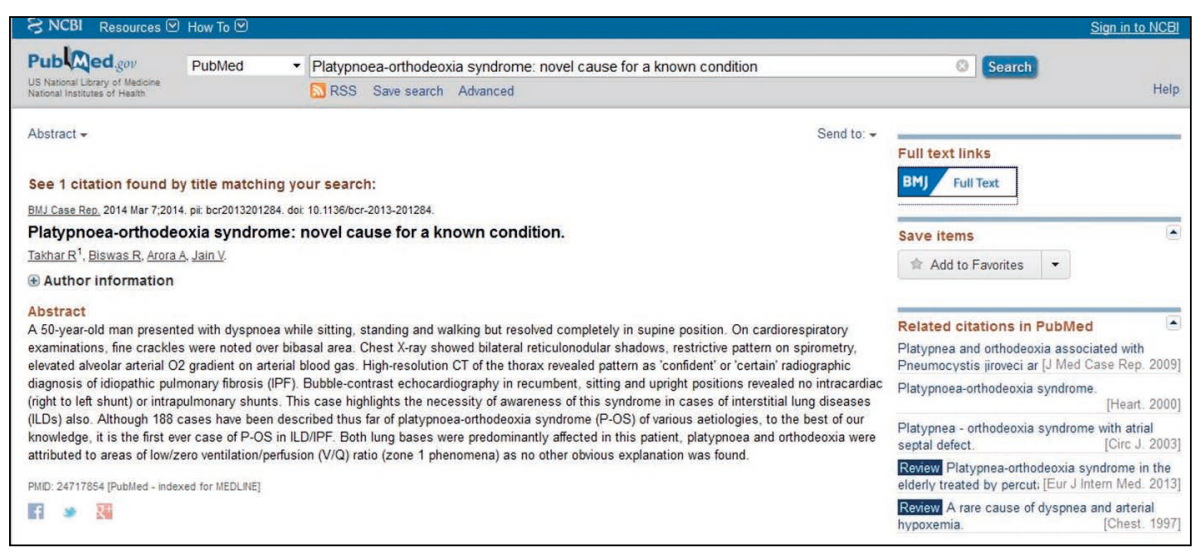

Fig. 7 Another case from UDHC

female feticide and Arogya Maternal Care which focuses on preventative care to reduce maternal mortality. The UDHC global community plans to test the effectiveness of these projects for community based action research in collaboration with ThinkWell by using their Public Led Online Trials (PLOT) with full methodological trials support, a secure platform, electronic data capture, ethical oversight and researcher training with the understanding that the platform will be adapted it to the UDHC population needs [21]. UDHC and ThinkWell have a steering committee of international experts, local practitioners, researchers and external consultants in place to guide the progres- 
sion of this stage. The users of the network will also be consulted for the purpose of gaining their feedback.

\section{Discussion}

"The job of the human being [in the digital age] is to become skilled at locating relevant valid data for their needs. In the sphere of medicine, the required skill is to be able to relate the knowledge generated by the study of groups of patients or populations to that lonely and anxious individual who has come to seek help."

Sir Muir Gray, 2001

In the UDHC model [16] there is room for innovation in medical education not only for the medical students but also for patients, clinicians and other stakeholders. Users of the network are privileged to observe how medicine intersects with life over time [22].

One belief/hypothesis around this is: If we can advance medical education (almost an MBBS level) to patient and public understanding without resorting to simplistic pamphlets or overly curated medical language terms then not only will patients be empowered, but even MBBS doctors will be buoyed up automatically in their knowledge as they will consistently be challenged by relationship to use the information and become part of the living evidence of informed patients who see themselves as in partnership with medical providers and their own healthcare choices.

UDHC has initiated the process in a unique and practical way with patients coming in to LN Medical College in Bhopal. Willing patients are taken to the anatomy dissection hall and they are shown the anatomical area where their own symptoms can be localized. This is helpful as often a medical diagnosis is separated into an anatomical diagnosis in other words we search for the source of the problem and then there is a parallel discussion concerning an etiologic-pathologic diagnosis or why is the reason, pathway or future of the problem [23].

This segmented approach is confusing for patients and medical students who started out seeing themselves as whole persons in need of care but are then later shocked by seeing their parts sectioned off for diagnosis and intervention with no room for their life values or personal characteristics attached [24]. Bringing patients to the table empowers them as they see the anatomy for themselves and become participants in the conversation and medical decision-making process so healthcare words are spoken with them instead of only about them. Teaching patients in this manner has manifold outcomes.

They can visualize their problem in a more tangible way and we have found that even when the condition is serious patients who "see" the truth are less anxious and better prepared to contribute to their own healing process as the darkness of the mystery of the ailment one can not see is stripped away.

When the public comes face to face with death, the corpse teaches them without words the inevitability of the fact that their currently functioning human machine has to stop one day. This can be a powerful motivator for difficult lifestyle changes.

A respect is engendered for our corpses/ cadavers who were the gift of very evolved humans. UDHC has created large framed photographs of these people outside the dissection hall. Many patients and students share that they are inspired by their pictures and the stories they have left as their legacy. Patients and students later themselves express a desire to donate their own bodies toward learning (those who previously had not given this area any thought).

Nursing students and interns are introduced to work underway within the dissection hall. In reality our entire treating team participates, usually after our rounds. This provides ample opportunity for the nursing students to practice intramuscular injection techniques in the cadavers, while our interns are able to practice intra-articular injections as well as more challenging types of interventions many of which are still to be fully developed. In short expertise is developed under safe conditions and with mentors in place so that trainees can strengthen diagnostic skills, approaches to the desperately ill and technical proficiency so they are prepared to deal with future patients in a climate of practical expertise and emotional readiness.

\section{Conclusion}

"It is my aspiration that health finally will be seen not as a blessing to be wished for, but as a human right to be fought for."

United Nations Secretary-General

Kofi Annan

UDHC is working to close health inequality gaps in rural India. This model is developed within an interdisciplinary exchange through a multiplicity of cultures to promote a scalable, accessible interface for the benefit of healthcare quality.

Hans Rosling [25] shares in his TED talks that gross national product is not the only driver for improved health but that the most valuable indicator is public knowledge and health literacy. Indeed without health literacy there is no real evidence based shared medical decision-making. It is the goal of UDHC to improve health literacy through collaborative conversation centered learning in local health care environments and over the Internet [7].

\section{Acknowledgements}

We are grateful to our patients, social workers, IT developers, students, research assistants and Tabula Rasa members.

\section{Declaration Related to the Use of Human Subjects}

The study complied to the codes as provided by the WMA Declaration of Helsinki - Ethical Principles for Medical Research Involving Human Subjects see - http://www. wma.net/en/30publications/10policies/b3/

We the authors hereby certify that no human subjects were directly involved as this contained secondary reporting on primary research for which full ethics approvals and consents were obtained although any examples used were obtained from participants who have given proper consent as obtained for the use of human participants.

\section{Competing Interests}

Purkayastha, Price, Jai Ganesh and Biswas and Otero have no competing or financial interests to disclose other than their interest in the growth and development of participatory medicine, research and neuroscience. Price and Biswas have acted in the role of volun- 
Purkayastha et al.

teer consultants in collaborative community research and intervention projects.

\section{References}

1. Price A, Biswas T, Biswas R. Person-centered healthcare in the information age: Experiences from a user driven healthcare network. Eur J Pers Centered Healthc 2013;1(2):385-93. Available from: http://ubplj.org/index.php/ejpch/article/ view/766

2. Chandra S, Price A, Biswas T, Bera K, Biswas R. User Driven Learning: Blending the Best of Clinical Medicine and Humanities to Infuse "Joy" into the Medical Curriculum. Int J User-Driven Healthc 2013;3(3):116-21. Available from: http:/ services.igi-global.com/resolvedoi/resolve.aspx?doi=10.4018/ijudh.2013070109

3. Price A, Chandra S, Bera K, Biswas T, Chatterjee $\mathrm{P}$, Wittenberg $\mathrm{R}$, et al. Understanding Clinical Complexity Through Conversational Learning in Medical Social Networks: Implementing User-Driven Health Care. In: Sturmberg JP, Martin $\mathrm{CM}$, editors. Handbook of Systems and Complexity in Health SE - 44 [Internet]. Springer New York; 2013. p. 767-93. Available from: http://dx.doi. org/10.1007/978-1-4614-4998-0_44

4. Price A, Chatterjee P, Biswas R. Time for Person Centered Research. Ann Neurosci 2014 Apr;21(2):37-40.

5. Biswas T, Biswas R, Bera K. BMJ Blogs: BMJ Case Reports blog » Blog Archive » Creating secondary learning resources from the BMJ Case Reports through social-media based discussion groups [Internet]. BMJ Blogs. 2011 [cited 2014 Dec 28]. Available from: http://blogs.bmj.com/case-reports/2011/10/28/creating-secondary-learning-resources/

6. McDonald K, Schultz E, Albin L, Pineda N, Lonhart J, Sudaram V, et al. Care coordination measures atlas. Updated June 2014. 2014 [cited 2014 Dec 28];(June). Available from: http://scholar. google.com/scholar?hl=en\&btnG=Search\&q=intitle:Coordination+Measures+Atlas $\# 0$

7. Nelson WL, Moser RP, Han PKJ. Exploring ob- jective and subjective numeracy at a population level: findings from the 2007 Health Information National Trends Survey (HINTS). J Health Commun 2013;18(2):192-205. Available from: http:// www.ncbi.nlm.nih.gov/pubmed/23066837

8. Chau JP-C, Lee DT-F, Yu DS-F, Chow AY-M, Yu W-C, Chair S-Y, et al. A feasibility study to investigate the acceptability and potential effectiveness of a telecare service for older people with chronic obstructive pulmonary disease. Int J Med Inform 2012;81(10):674-82. Available from: http://www. ncbi.nlm.nih.gov/pubmed/22789911

9. Stewart EE, Crabtree BF, Miller WL. Implementing the Patient-Centered Medical Home : Observation and Description of the National Demonstration Project. 2010;21-32.

10. Stacey D, O'Connor AM, Graham ID, Pomey M. Randomized controlled trial of the effectiveness of an intervention to implement evidence-based patient decision support in a nursing call centre. J Telemed Telecare 2006;12(8):410-5.

11. Price A, Chatterjee P, Biswas R. time for person centered research in neuroscience: users driving the change. Ann Neurosci 2014;21(2):37-40. Available from: http://www.ncbi.nlm.nih.gov/pmc/ articles/PMC4117163/

12. Price A. BMJ Blogs: The BMJ» Blog Archive» Amy Price: Patients doing research for themselves [Internet]. BMJ Blogs. 2014 [cited 2014 Dec 8]. Available from: http://blogs.bmj.com/ bmj/2014/10/17/amy-price-patients-doing-research-for-themselves/

13. Monteiro E, Pollock N, Hanseth O, Williams R. From artefacts to infrastructures. Comput Support Coop Work CSCW An Int J 2013;22(46):575-607.

14. Pironti BJP. Key Elements of a Threat and Vulnerability Management Program. 2006;1-5.

15. BMJ. BMJ Case Reports Student Electives [Internet]. BMJ 2014 [cited 2014 Dec 27]. Available from: http://journals.bmj.com/site/marketing/ landing-pages/Indian_Caseelectives.xhtml

16. UDHC. Welcome to the User-driven health network [Internet]. 2014 [cited 2014 Apr 25]. Available from: http://care.udhc.co.in/

17. Sakagianni K, Evrenoglou D, Mytas D, Vavuranakis M. Platypnea-orthodeoxia syndrome related to right hemidiaphragmatic elevation and a "stretched" patent foramen ovale. BMJ Case Rep 2012 Dec 10 Available from: http://casereports. bmj.com/content/2012/bcr-2012-007735.abstract

18. Price A, Burls A. ThinkWell [Internet]. 2013. Available from: http://ithinkwell.org

19. Price A, Burls A. PLOT-IT Public Led Online Trials Infrastructure and Tools. Force 2015 [Internet]. Oxford UK: Force2015; 2015. Available from: https://www.researchgate.net/publication/269700357_PLOT-IT_Public_Led_Online_Trials_Infrastructure_and_Tools

20. R3G. Mission Arogya [Internet]. 2007 [cited 2014 Dec 27]. Available from: http://www.missionarogya.org/

21. Burls A, Price A, Brice A. PLOT-IT: Public Empowerment and Engagement in Clinical Trials. Medicine 20 Conference [Internet]. JMIR Publications Inc., Toronto, Canada; 2014 [cited 2014 Dec 6]. Available from: http://www.medicine20congress.com/ocs/index.php/med/med2014b/ paper/view/2534

22. Chatterjee S, Price A, Biswas R. Turning the tables on learning attrition in medical students : Introducing User Driven Healthcare. Indian J Med Informatics 2014;6-11.

23. Chalmers I. What do I want from health research and researchers when I am a patient? BMJ 1995 May 20;310(6990):1315-8. Available from: http://www.pubmedcentral.nih.gov/articlerender. fcgi?artid=2549685\&tool=pmcentrez\&rendertype $=$ abstract

24. Greenhalgh T, Howick J, Maskrey N. Evidence based medicine: a movement in crisis? BMJ. 2014 Jun 13;348:g3725. Available from: http://www. bmj.com/cgi/doi/10.1136/bmj.g3725

25. Rosling H. Hans Rosling: Stats that reshape your world-view [Internet]. TED. 2012 [cited 2014 Dec 6]. Available from: https://www.youtube.com/ watch? $=$ hVimVzgtD6w

\section{Correspondence to:}

Dr. Amy Price

Department of Primary Health Care Sciences

University of Oxford

Oxford, UK

E-mail: dr.amyprice@gmail.com 